\title{
Perencanaan Sistem Pengolahan Air Limbah Domestik di Kecamatan Sidoarjo, Kabupaten Sidoarjo
}

\author{
Fajar Arinal Khaq dan Agus Slamet \\ (ITS) \\ e-mail:suga@its.ac.id
}

Departemen Teknik Lingkungan, Fakultas Teknik Sipil dan Perencanaan, Institut Teknologi Sepuluh Nopember

\begin{abstract}
Abstrak-Air limbah domestik dari rumah tangga yang tidak diolah menyebabkan berbagai pencemaran lingkungan. Sustainable Development Goals (SDGs) dan Rencana Pembangunan Jangka Menengah Nasional (RPJMN) tahun 2015-2019 telah mentargetkan 100:0:100 dimana salah satu aspeknya adalah air limbah, maka Kabupaten Sidoarjo direncanakan akan membangun Sistem Penyaluran Air Limbah (SPAL) dan Instalasi Pengolahan Air Limbah (IPAL). Pada umumnya, IPAL dipandang buruk karena menimbulkan bau, maka dibutuhkan inovasi teknologi hijau. Daerah perencanaan terletak di 3 Kelurahan yaitu Kelurahan Magersari, Jati, dan Pagerwojo yang dibagi menjadi 3 cluster dengan jumlah penduduk keselurahan 37.535 orang. Desain SPAL yang digunakan adalah shallow sewer serta kombinasi IPAL dengan sistem Anaerobic Baffle Reactor (ABR) dan Hybrid Aero-Plant Reactor System (HAPS) secara komunal. Kualitas influen yang diolah adalah BOD $162 \mathrm{mg} / \mathrm{L}$, COD $268 \mathrm{mg} / \mathrm{L}$, TSS $210 \mathrm{mg} / \mathrm{L}$, amonia 48,57 mg/L, dan total coliform $22 \times 108 \mathrm{MPN} / 100 \mathrm{~mL}$. Baku mutu yang digunakan adalah peraturan Kementrian Lingkungan Hidup No. 68 Tahun 2016 tentang air limbah domestik. Hasil desain menunjukan sistem penyaluran menggunakan pipa PVC dengan diameter 100-200 mm. Lahan yang dibutuhkan untuk IPAL cluster I seluas $250 \mathrm{~m}^{2}$, cluster II seluas $235 \mathrm{~m}^{2}$, dan cluster III seluas $122,5 \mathrm{~m}^{2}$. Anggaran biaya investasi yang dibutuhkan untuk cluster I sebesar Rp 17.936.035985, kemudian untuk cluster II sebesar Rp 15.040.856.211, dan untuk cluster III sebesar Rp 8.183.280.455. Anggaran biaya operasi dan pemeliharaan dibutuhkan sebesar Rp 8.000/Kepala Keluarga setiap bulan.
\end{abstract}

Kata Kunci-Aerobic, Aerobic, Organica, Sidoarjo, SPAL.

\section{PENDAHULUAN}

I NDONESIA sebagai negara berkembang masih banyak masyarakatnya yang membuang limbah secara sembarangan ke lingkungan hingga tercemar. Pencegahan lingkungan yang tercemar telah diupayakan dengan melakukan pengendalian pencemaran melalui UU No 32 tahun 2009 tentang perlindungan dan pengelolaan lingkungan hidup [1]. Sustainable Development Goals (SDGs) merupakan sebuah kesepakatan pengganti Millenium Development Goals (MDGs) yang berlaku pada tahun 2015 - 2030, dimana salah satu dari tujuannya yaitu pengolahan air limbah rumah tangga yang diolah sesuai dengan standar nasional [2]. Disisi lain, target Rencana Pembangunan Jangka Menengah Nasional (RPJMN) tahun 2015-2019 yakni 100: 0: 100, dimana 100\% untuk pelayanan air bersih, 0\% kawasan kumuh, dan 100\% sanitasi yang layak juga belum sesuai. Salah satu objek nyata pengolahan air limbah yaitu dengan Sistem Penyaluran Air Limbah (SPAL). SPAL yang dilakukan secara tepusat sudah banyak dilakukan negara besar dalam pengelolaan air limbah perkotaan, namun di Indonesia SPAL yang digunakan mayoritas menggunakan sistem komunal. Pada kondisi ideal, sistem terpusat menjadi pilihan, namun membutuhkan biaya yang mahal, sehingga di Indonesia sistem komunal yang banyak digunakan, disamping biaya konstruksi murah, lahan yang dibutuhkan juga tidak terlalu besar [3].

Sidoarjo merupakan wilayah yang menjadi penyangga kota metropolitan Surabaya. Terdapat dua kelurahan yang termasuk dalam kawasan pemukiman padat penduduk yaitu Kelurahan Magersari dengan jumlah kepala keluarga (KK) sebanyak 4.087 dan Kelurahan Jati sebanyak 3.422 [4]. Berdasarkan pengamatan di lapangan, dua kelurahan tersebut masih membuang greywater melalui drainase, sedangkan blackwater mayoritas sudah ditampung pada tanki septik. Tingginya pertambahan penduduk linear dengan bertambahnya kawasan pemukiman baru, sehingga ketersediaan lahan di Kabupaten Sidoarjo mulai berkurang, sesuai dengan Peraturan Daerah Kabupaten Sidoarjo No 6 Tahun 2009, tentang Rencana Tata Ruang Wilayah tahun 2009-2029, bahwa dalam kawasan yang belum memiliki sistem pembuangan air limbah setempat dan/atau terpusat, setiap orang perseorangan atau kelompok masyarakat dilarang membuang air limbah secara langsung tanpa pengolahan ke media lingkungan. Selain itu sistem pengelolaan air limbah masuk dalam strategi pengembangan prasarana wilayah kabupaten sesuai dengan peraturan daerah [5].

Pada beberapa kalangan masyarakat, IPAL dipandang buruk karena menimbulkan bau, maka dibutuhkan inovasi teknologi hijau. Hybrid Aero-Plant Reactor System (HAPS) memiliki konsep berdasarkan organica ecotechnology merupakan teknologi baru dalam pengolahan air limbah dimana teknologi ini merupakan kombinasi antara pengolahan konvensional dan modern dengan konsep ekologis. Selain itu, Organica dapat menjadi estetika lingkungan karena menggunakan tanaman dalam aplikasinya [6]. Sistem HAPS dipilih karena memiliki kelebihan yaitu menggunakan tanaman yang akarnya dijadikan sebagai media melekatnya mikroba sehingga membentuk biofilm, kemudian reduksi lumpur tinggi, efisiensi penggunaan energi kecil, serta lahan yang digunakan kecil sehingga cocok untuk daerah padat penduduk [7]. Untuk pengolahan primer, digunakan unit Anaerobic Baffled Reactor (ABR) karena memiliki kelebihan, diantaranya efisiensi pengolahan tinggi, lahan yang dibutuhkan kecil, biaya 
pengoperasian dan perawatan mudah, dapat menerima beban shock loading [8].

\section{METODE PERENCANAAN}

\section{A. $S P A L$}

Jenis penyaluran yang digunakan adalah shallow sewer dengan sistem pengaliran secara gravitasi. Shallow sewer dapat dipasang dengan secara dangkal yakni slope minimum $0,4 \mathrm{~m}$ dari permukaan tanah. Berdasarkan survey dilapangan slope di wilayah perencanaan tidak terlalu landai sehingga sesuai dengan kriteria shallow sewer. Ketentuan lain yang perlu diperhatikan jika menggunakan sistem gravitasi antara lain sebagai berikut.

a) Konstanta Manning (n) $=0.009$ (pipa PVC) [9]

b) Diameter pipa minimum $=100 \mathrm{~mm} \mathrm{[10]}$

c) kecepatan minimum $=0.5 \mathrm{~m} / \mathrm{s}$ pada saat debit ratarata atau peak

d) kecepatan maksimum $=2.5-3.0 \mathrm{~m} / \mathrm{s}$

e) Tinggi renang $(\mathrm{d} / \mathrm{D})=0.5[11]$

Untuk mengetahui karakteristik air limbah yang akan diolah maka perlu dilakukan sampling di lokasi perencanaan. Sampel diambil pada saat puncak yaitu pagi hari pukul 06.00 waktu setempat pada titik outlet saluran didekat sumber. Selanjutnya menentukan debit air limbah yang diperoleh dari data penggunaan air bersih. Debit air limbah kemudian ditentukan dengan mengasumsi air limbah yang dihasilkan adalah $80 \%$ dari debit air bersih. Debit peak didapat dengan menentukan faktor peak, sedangkan untuk debit minimum ditentukan dari jumlah penduduk terlayani yang diperoleh dari persamaan Fair dan Geyer [12].

fpeak $\quad=\left(18+\mathrm{P}^{0.5}\right) /\left(4+\mathrm{P}^{0.5}\right)$

$\mathrm{Q} \min =\frac{1}{5} \times\left(\frac{\text { Jumlah Penduduk }}{1000}\right)^{0,2} \times \mathrm{Q}$ ave

\section{B. IPAL}

IPAL yang digunakan diantaranya yaitu unit sumur pengumpul sebagai unit awal yang menerima pipa SPAL paling akhir, kemudian air limbah diangkat dengan pompa submersible menuju unit bak distribusi. Selanjutnya air limbah didistribusikan secara merata menuju unit ABR yang akan mengalami kondisi anaerobic, setelah itu masuk kedalam unit HAPS yang akan mengalami kondisi aerobic.

\section{HASIL DAN PEMBAHASAN}

Daerah pelayanan terdiri dari Kelurahan Magersari, Jati, dan Pagerwojo yang dibagi menjadi 3 cluster dengan jumlah penduduk keselurahan 37.535 orang. Setiap Kepala Keluarga diasumsikan memiliki 5 orang. Berikut merupakan jumlah penduduk yang dilayani akan tersaji pada Tabel 1 .

Tabel 1.

Jumlah Kepala Keluarga dan Penduduk

\begin{tabular}{cccc}
\hline \hline & & Kepala & Jumlah \\
Keluarga & (KK) & $\begin{array}{c}\text { Penduduk } \\
\text { (orang) }\end{array}$ \\
\hline 1 & Desa/Kelurahan & 3066 & 15330 \\
2 & Magersari & 2730 & 13650 \\
3 & Jati & 1711 & 8555 \\
\hline \hline
\end{tabular}

\section{A. Air Limbah}

Perhitungan debit air limbah domestik diperoleh setelah mengetahui data penggunaan air bersih Kabupaten Sidoarjo yaitu 126,92 L/orang.hari, kemudian diambil angka $80 \%$ dari air bersih merupakan debit air limbah yaitu 102 L/orang.hari. faktor peak untuk IPAL memiliki perbedaan dengan perhitungan SPAL dimana untuk sistem penyaluran digunakan faktor jumlah penduduk yang dilayani sehingga memiliki faktor peak bervariasi setiap salurannya, sedangkan untuk IPAL memiliki kriteria sendiri yang dilihat dari aspek pelayanan cakupan wilayah yaitu minimum $(1,3-1,75)$, maka dalam perencanaan ini faktor peak yang digunakan adalah 1,5. Berikut merupakan debit seluruh cluster yang disajikan pada Tabel 2.

Tabel 2.

Debit untuk IPAL setiap cluster

\begin{tabular}{ccccc}
\hline \hline \multirow{2}{*}{ Cluster } & Jumlah Penduduk & Q ave & Qpeak & Qmin \\
\cline { 2 - 5 } & (orang) & $\mathrm{m}^{3} / \mathrm{hari}$ & $\mathrm{m}^{3} / \mathrm{hari}$ & $\mathrm{m}^{3} / \mathrm{hari}$ \\
\hline 1 & 15330 & 1564 & 2345 & 540 \\
2 & 13650 & 1392 & 2088 & 470 \\
3 & 8555 & 873 & 1309 & 268 \\
\hline \hline
\end{tabular}

Untuk mengetahui karakteristik air limbah awal dilakukan sampling pada lokasi perencanaan. Sampling dilakukan pada malam hari dan pagi hari saat mencapai debit puncak dilokasi yang berbeda. Kedua sampel menghasilkan karakteristik yang berbeda, maka diambil angka yang paling tinggi untuk angka aman yaitu pagi hari. Berikut merupakan karakteristik awal air limbah domestik yang disajikan pada Tabel 3.

Tabel 3.

Karakteristik air limbah domestik

\begin{tabular}{cccc}
\hline \hline Parameter & Satuan & $\begin{array}{c}\text { Konsentrasi } \\
\text { Awal }\end{array}$ & Baku Mutu \\
\hline $\mathrm{pH}$ & - & 6,95 & $6-9$ \\
$\mathrm{TSS}$ & $\mathrm{mg} / \mathrm{L}$ & 210 & 30 \\
$\mathrm{COD}$ & $\mathrm{mg} / \mathrm{L}$ & 268 & 100 \\
$\mathrm{BOD}$ & $\mathrm{mg} / \mathrm{L}$ & 162 & 30 \\
& & 0,6 & - \\
Rasio BOD/COD & - & 20 & 5 \\
Minyak \& lemak & $\mathrm{mg} / \mathrm{L}$ & 48,57 & 10 \\
Amonia & $\mathrm{mg} / \mathrm{L}$ & $22 \times 10^{8}$ & 3000 \\
Total Koliform & $\mathrm{MPN} / 100 \mathrm{~mL}$ & & \\
\hline \hline
\end{tabular}

\section{B. Perencanaan SPAL}

Perencanaan SPAL awal yaitu dengan menghitung pembebadan saluran yang bertujuan untuk mengetahui berapa beban yang disalurkan. Dalam pembebanan saluran faktor peak setiap saluran berbeda, karena penduduk yang dilayani juga berbeda. Berikut merupakan contoh perhitungan faktor peak saluran primer akhir pada cluster I.

$$
\begin{aligned}
\text { fpeak } & =\left(18+\mathrm{P}^{0.5}\right) /\left(4+\mathrm{P}^{0.5}\right) \\
& =\left(18+15.330^{0.5}\right) /\left(4+15.330^{0.5}\right) \\
& =1,1
\end{aligned}
$$


Setelah dilakukan perhitungan pembebanan saluran, maka dapat dicari diameter pipa yang dibutuhkan disetiap saluran. Diperoleh diameter pipa untuk saluran tersier $100 \mathrm{~mm}$, untuk saluran sekunder $150 \mathrm{~mm}$, dan untuk saluran primer $200 \mathrm{~mm}$. Panjang pipa antara $30 \mathrm{~m}$ sampai $600 \mathrm{~m}$. Kedalaman penanaman pipa SPAL pada titik akhir menuju unit sumur pengumpul berada pada $2-3 \mathrm{~m}$ dari permukaan tanah.

Bangunan pelengkap yang digunakan adalah bak kontrol yang diletakkan pada setiap masing-masing rumah sehingga jumlahnya sama dengan jumlah KK yang dilayani yaitu untuk cluster I sebanyak 3.066 bak kontrol, cluster I sebanyak 2.730 bak kontrol, dan cluster III sebanyak 1.711 bak kontrol. Selain itu bangunan pelengkap yang digunakan adalah manhole saluran dengan jenis dan jumlah disajikan pada Tabel 4.

Tabel 4.

Jenis dan jumlah manhole

\begin{tabular}{ccccc}
\hline \hline No. & Jenis Manhole & $\begin{array}{c}\text { cluster I } \\
\text { buah }\end{array}$ & $\begin{array}{c}\text { cluster II } \\
\text { buah }\end{array}$ & $\begin{array}{c}\text { cluster III } \\
\text { buah }\end{array}$ \\
\hline 1 & Lurus & 121 & 114 & 30 \\
2 & Belokan & 26 & 19 & 22 \\
3 & Pertigaan & 56 & 43 & 18 \\
4 & Perempatan & 2 & 7 & 4 \\
5 & Drop & 1 & 1 & 1 \\
& Total & 206 & 184 & 75 \\
\hline \hline
\end{tabular}

Berikut merupakan hasil disain SPAL untuk cluster I yang disajikan pada Gambar 1.

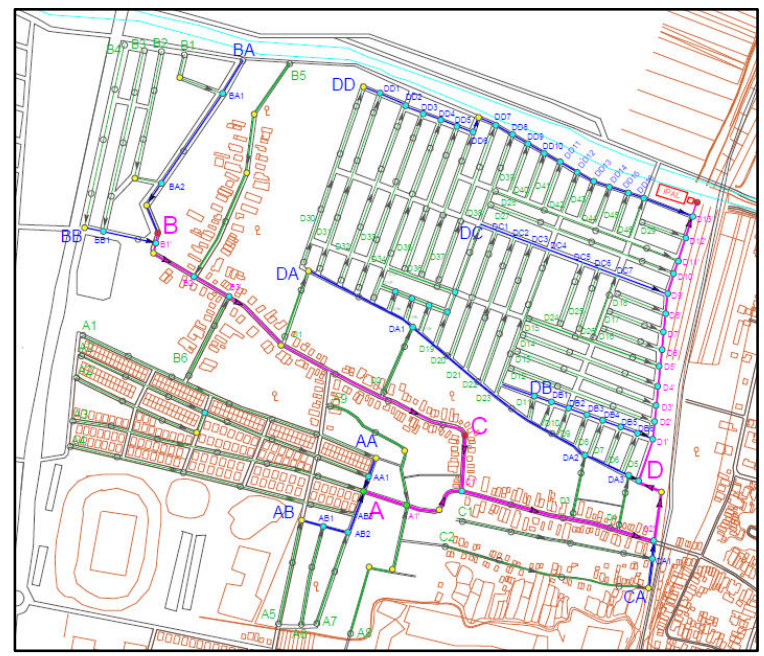

Gambar 1. SPAL cluster I.

Penyisihan amonia $\left(\mathrm{NH}_{3}\right)$ dapat terjadi di SPAL disebabkan adanya manhole yang membuat air limbah mengalami terjunan sehingga terjadi turbulensi yang membuat oksigen masuk kedalam air limbah dan terjadi nitrifikasi yaitu proses pelepasan kandungan amonia dari nitrit menjadi nitrat dan terlepas dalam bentuk $\mathrm{N}_{2}$ gas. Karena banyaknya jumlah manhole maka diperkirakan efisiensi removal dari amonia di SPAL sebesar $80 \%$. Berikut merupakan perhitungan dari removal amonia.

Konsentrasi amonia awal $=48,57 \mathrm{mg} / \mathrm{L}$,

Efisiensi removal di SPAL $=80 \%$
Konsentrasi amonia

$$
\begin{aligned}
& =(100-80) \% \times 48,57 \mathrm{mg} / \mathrm{L} \\
& =9,7 \mathrm{mg} / \mathrm{L}
\end{aligned}
$$

\section{Perencanaan IPAL}

Pada cluster I, Sumur pengumpul direncanakan sebagai unit pertama dengan kedalaman dari muka tanah menuju pipa inlet dari SPAL adalah 3,1 m. Waktu detensi (td) 3,5 menit maka diperoleh dimensi sumur pengumpul dengan ukuran panjang $\mathrm{x}$ lebar x tinggi adalah $2 \mathrm{~m}$ x 1,5 m x $2 \mathrm{~m}$. Kemudian air limbah dipompa keatas dengan pompa submersible menuju bak distribusi. Waktu detensi bak distribusi 1 menit maka diperoleh dimensi dengan ukuran panjang $\mathrm{x}$ lebar $\mathrm{x}$ tinggi adalah $1 \mathrm{~m} \times 1 \mathrm{~m} \times 1,6 \mathrm{~m}$.

Air limbah setelah melalui bak distribusi, selanjutnya didistribusikan menuju unit ABR dan HAPS. Debit yang masuk terlalu besar sehingga ABR dibagi menjadi 3 bagian secara pararel. Pada unit ABR terdapat zona pengendapan yang terletak pada kompartemen 1 dan 4 kompartemen yang berupa baffle. Pada kompartemen 1 terdapat grease trap untuk memisahkan minyak dan lemak. Persen pengolahan minyak lemak pada grease trap sebesar 95\% (Wongthanate, et al., 2014). Berikut merupakan perhitungan konsentrasi minyak \& lemak dalam air limbah.

Konsentrasi awal $=20 \mathrm{mg} / \mathrm{L}$,

Persen pengolahan $=95 \%$

Konsentrasi akhir $=(100-95) \% \times 20 \mathrm{mg} / \mathrm{L}$ $=1 \mathrm{mg} / \mathrm{L}$

Waktu detensi untuk zona pengendapan ABR yaitu 3 jam sehingga diperoleh efisiensi removal TSS 68\% dan BOD sebesar 38\% melalui grafik hubungan waktu detensi dan persen removal.

Dimensi zona pengendapan ABR dengan ukuran panjang $\mathrm{x}$ lebar x tinggi adalah $10,8 \mathrm{~m} \times 3 \mathrm{~m} \times 4 \mathrm{~m}$ untuk satu bagian. kompartemen II yang berjumlah 4 buah didisain dengan parameter Organic Loading Rate (OLR), BOD strength, suhu, jumlah kompartemen, Hidraulic Retantion Time (HRT) untuk menentukan efisisensi removal BOD yaitu 38\%, sehingga diketahui efisiensi removal COD yaitu 35,7\% dan TSS 55,4\%. Dimensi kompartemen II ABR dengan ukuran panjang $\mathrm{x}$ lebar $\mathrm{x}$ tinggi adalah $2 \mathrm{~m} \times 3 \mathrm{~m} \times 4 \mathrm{~m}$ untuk satu bagian.

Unit setelah ABR adalah HAPS yang dipasang secara seri dengan inlet berupa pintu air. Pada cluster III tidak digunakan unit HAPS karena faktor jumlah penduduk yang dilayani sedikit sehingga biaya menjadi mahal. Dimensi yang direncanakan untuk HAPS pada cluster I dengan ukuran panjang x lebar x tinggi adalah 5,7 $\mathrm{m}$ x 9,4 $\mathrm{m}$ x $4 \mathrm{~m}$. Berikut merupakan hasil disain ABR dan HAPS cluster I yang disajikan pada Gambar 2. 


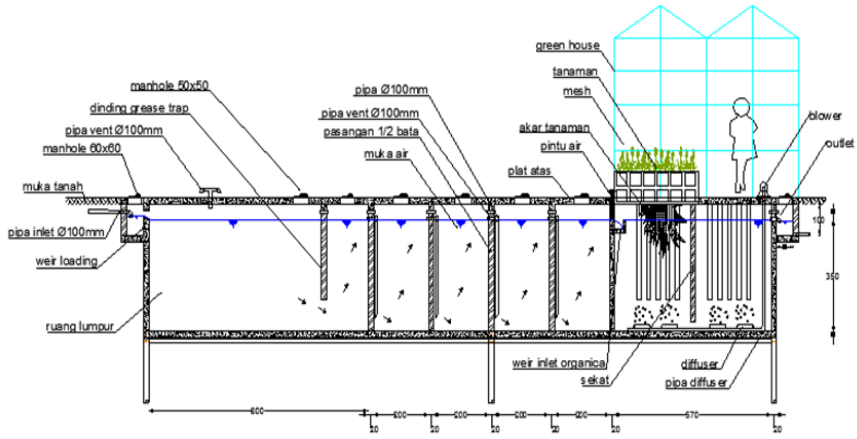

Gambar 2. Hasil perencanaan cluster I.

Bakteri e-coli atau patogen adalah bakteri yang hidup pada kondisi anaerob sehingga ketika diberikan kondisi aerob maka e-coli akan mati. Bakteri e-coli tidak bisa hidup ketika diberikan sinar UV atau sinar matahari. Penyisihan bakteri ecoli menggunakan pendekatan koefisien kematian e-coli $(\mathrm{Kb})$ dengan memperhatikan waktu detensi pada dan suhu, dalam hal ini suhu (T) HAPS yaitu $30^{\circ}$ dengan waktu detensi 2,2 jam.

Hasil akhir effluen yang telah diolah dengan unit IPAL ABR dan HAPS untuk cluster I dan II disajikan pada Tabel 5.

Tabel 5.

Effluen air limbah domestic cluster I \& II

\begin{tabular}{ccccc}
\hline \hline Parameter & Satuan & $\begin{array}{c}\text { effluen } \\
\text { ABR }\end{array}$ & $\begin{array}{c}\text { effluen } \\
\text { HAPS }\end{array}$ & $\begin{array}{c}\text { Baku } \\
\text { Mutu }\end{array}$ \\
\hline TSS & mg/L & 30 & 4 & 30 \\
COD & mg/L & 107 & 42 & 100 \\
$\begin{array}{c}\text { BOD } \\
\text { Minyak \& } \\
\text { lemak }\end{array}$ & mg/L & 63 & 22 & 30 \\
$\begin{array}{c}\text { Amonia } \\
\text { Total } \\
\text { Koliform }\end{array}$ & $\begin{array}{c}\text { mgN/L } \\
\text { mL } / 100\end{array}$ & 1 & 1 & 5 \\
\hline \hline
\end{tabular}

Efluen dari cluster III tanpa unit HAPS disajikan pada Tabel 6.

Tabel 6.

Effluen air limbah domestic cluster III

\begin{tabular}{ccc}
\hline \hline Parameter & Satuan & effluen ABR \\
\hline TSS & $\mathrm{mg} / \mathrm{L}$ & 30 \\
COD & $\mathrm{mg} / \mathrm{L}$ & 81 \\
BOD & $\mathrm{mg} / \mathrm{L}$ & 46,2 \\
Minyak \& lemak & $\mathrm{mg} / \mathrm{L}$ & 1 \\
Amonia & $\mathrm{mg} / \mathrm{L}$ & 9,7 \\
Total Koliform & MPN/100 mL & - \\
\hline \hline
\end{tabular}

\section{KESIMPULAN}

Berdasarkan perencanaan yang telah dilakukan, maka dapat diambil kesimpulan sebagai berikut:

1. Perencanaan SPAL dan IPAL

a. Daerah yang dilayani yaitu Kelurahan Magersari, Kelurahan Jati dan Kelurahan pagerwojo yang terbagi menjadi 3 Cluster dengan jumlah penduduk keselurahan yaitu 37.535 orang.

b. Sistem SPAL menggunakan sistem shallow sewer, sedangkan unit IPAL terdiri dari Sumur Pengumpul, Distribution Box, Anaerobic Baffled Reactor, dan HAPS.

c. Besar debit yang diolah dalam unit IPAL yaitu:

- Cluster I $=1.564 \mathrm{~m} 3 /$ hari

- $\quad$ Cluster II $=1.392 \mathrm{~m} 3 /$ hari

- $\quad$ Cluster III = $873 \mathrm{~m} 3 /$ hari.

d. Efluen hasil perencanaan IPAL dirancang memenuhi baku mutu Permen KLHK No. 68 Tahun 2016.

2. Rencana Anggaran Biaya SPAL dan IPAL

a. Anggaran Biaya total yang dibutuhkan sebesar:

- $\quad$ Cluster I = Rp 17,936,035,985

- $\quad$ Cluster II $=\operatorname{Rp~15,040,856,211~}$

- $\quad$ Cluster III = Rp 8,183,280,455

b. Biaya retribusi setiap kepala keluarga untuk operasi dan pemeliharaan yang dibayar melalui organisasi lingkungan setempat yaitu sebesar Rp 8.000/bulan

\section{DAFTAR PUSTAKA}

[1] Peraturan Menteri Lingkungan Hidup dan Kehutanan, "Pengendalian lingkungan tercemar UU Nomor 32 tentang perlindungan dan pengelolaan lingkungan hidup Tahun 2009," 2009.

[2] M. Hoelman and et al, "Panduan SDGs untuk pemerintah Daerah (Kota dan Kabupaten) dan Pemangku Kepentingan Daerah," 2015.

[3] Kementrian Pekerjaan Umum, "Buku 3 SPAL terpusat skala permukiman,” 2016.

[4] Badan Pusat Statistik, "Kecamatan Sidoarjo dalam angka," Sidoarjo, 2016.

[5] Pemerintah Kabupaten Sidoarjo, "Rencana Tata Ruang Wilayah Kabupaten Sidoarjo Tahun 2009-2029," Sidoarjo, 2009.

[6] Q. Yuje, W. Jiandong, and O. Hai, "The Application of Organica Ecological Technology in Residential Sewage Treatment," $J$. Environ. Prot. (Irvine,. Calif)., vol. 4, pp. 31-34, 2013.

[7] Anonymous, "www.OrganicaWater.com," 2015. [Online]. Available: www.OrganicaWater.com.

[8] Pamsimas, "Petunjuk Teknis Perencanaan Kegiatan Pamsimas Tingkat Masyarakat," Jakarta, 2011.

[9] IPEXAmerica, "Municipal Piping Systems," America, 2002.

[10] Kementerian Pekerjaan Umum, "Petunjuk Teknis Pembangunan Infrastruktur," 2013.

[11] P. Carl, "Planning of flushing station in sewer system," J. Civ. Eng. Technol., vol. 3, no. 2, 2007.

[12] G. M. Fair and J. C. Geyer, Water Supply and Wastewater Disposal. New York: John Wiley \& Sons, 1954. 